\title{
Palladium-Catalyzed Arylboration of Bicyclic Alkenes
}

Kai Yang ${ }^{\mathrm{a}}$ and Qiuling Song, ${ }^{\mathrm{a}, \mathrm{b}}$ *

${ }^{a}$ Institute of Next Generation Matter Transformation, College of Chemical Engineering at Huaqiao University, 668 Jimei Blvd, Xiamen, Fujian, 361021, P. R. China

${ }^{b}$ National Laboratory for Molecular Sciences, Institute of Chemistry, CAS, Beijing, 100190,

P. R. China

\section{Table of Contents}

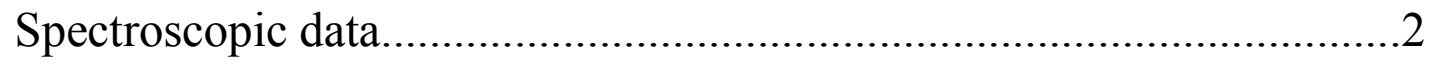




\section{Spectroscopic data}
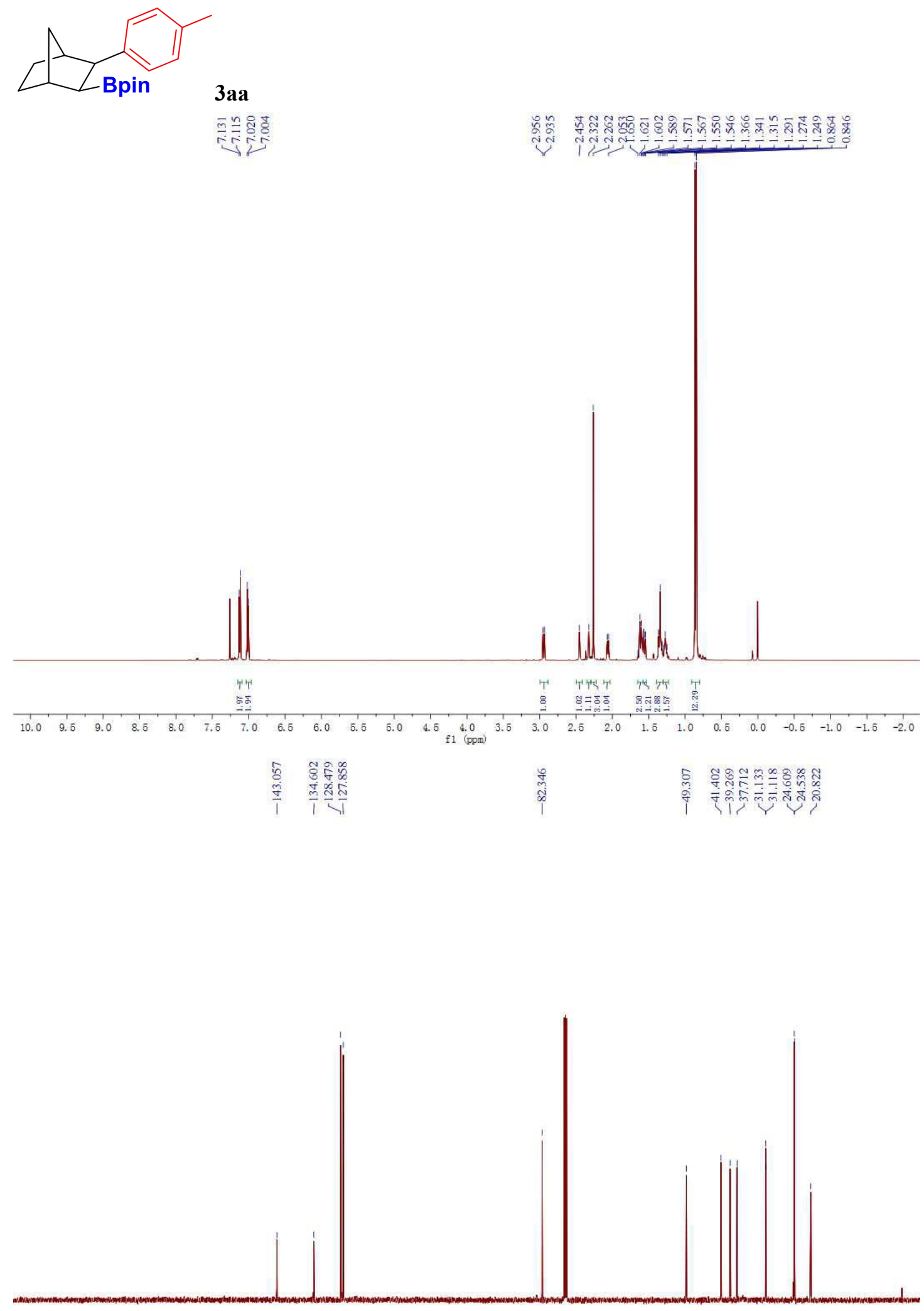

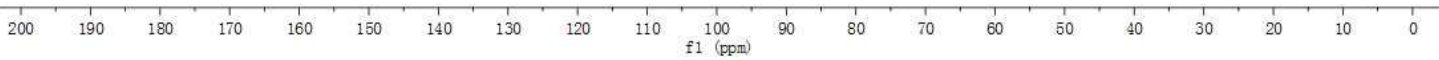


$Z_{\text {Bpin }}$

象

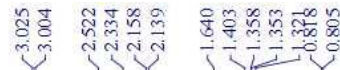

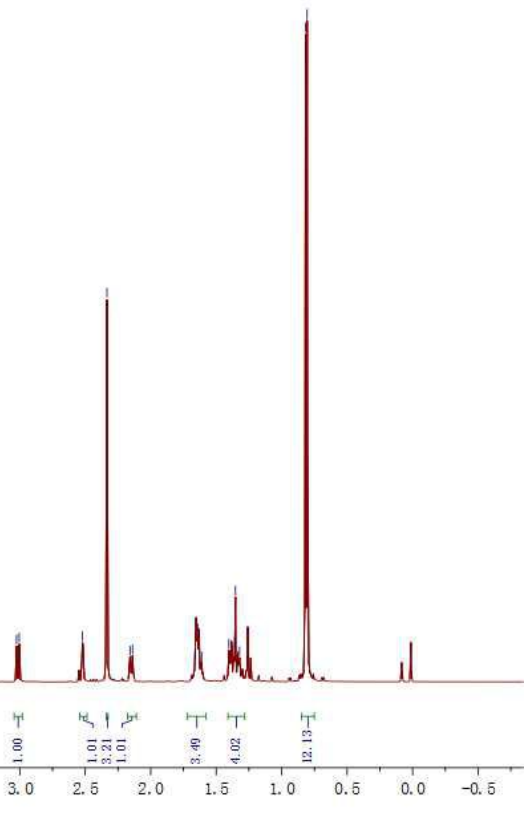

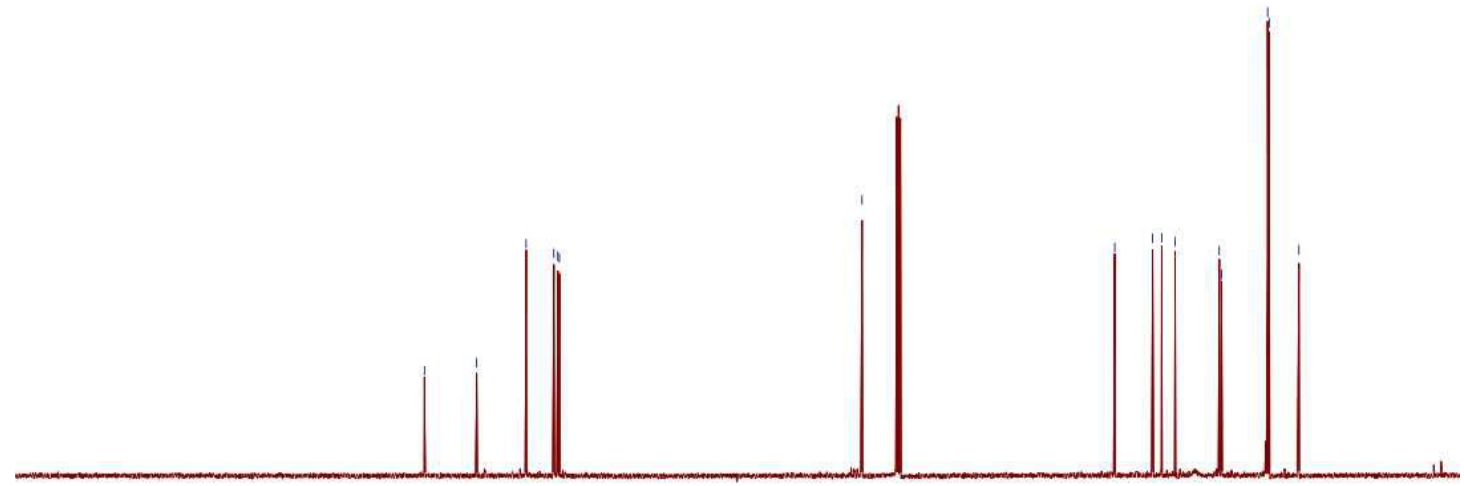

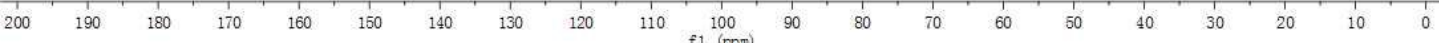


$C_{\text {Bpin }}$

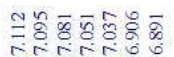

त्रin?
过素

it
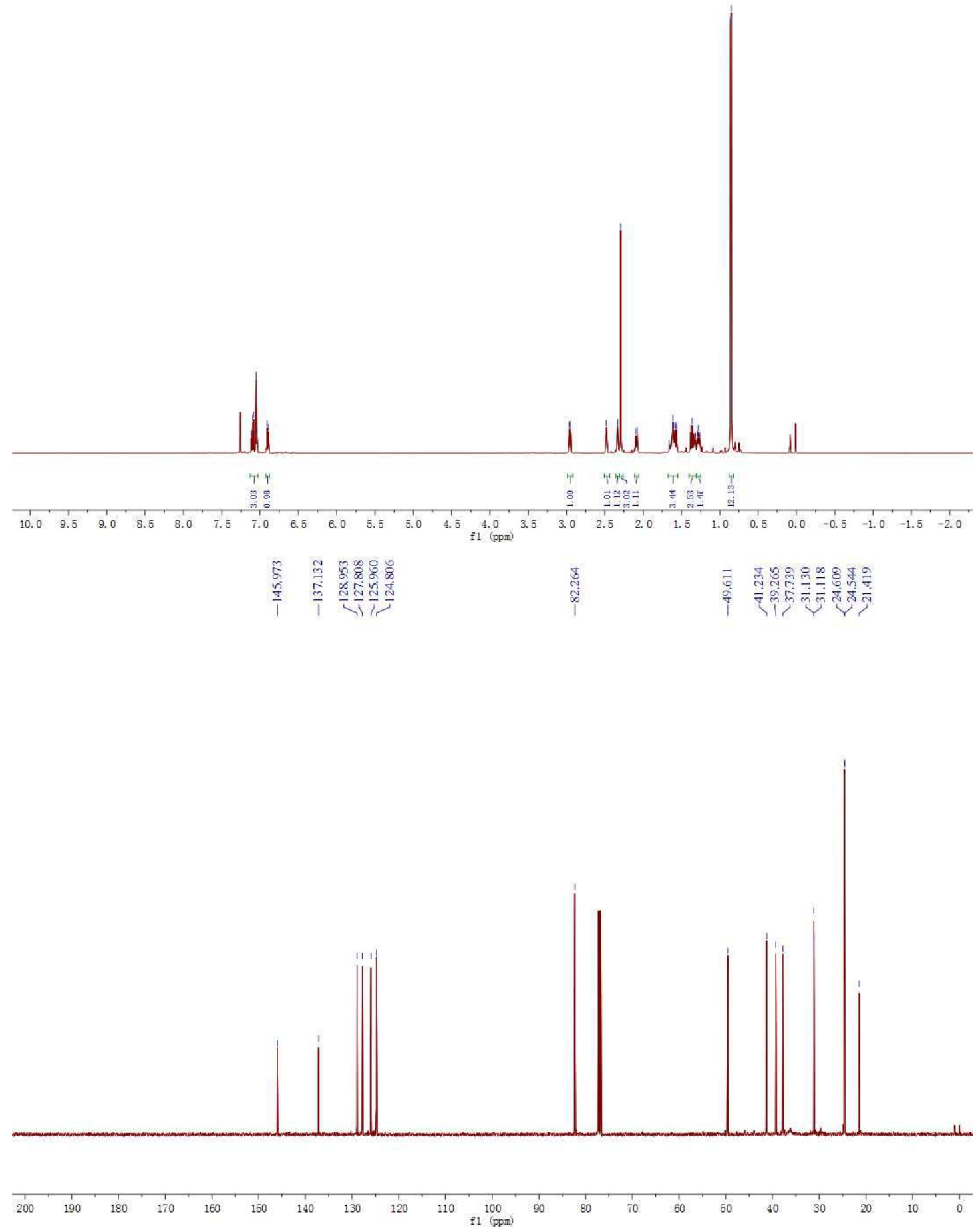


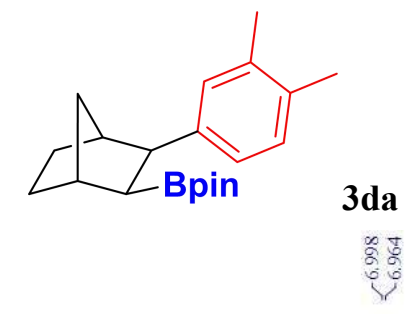

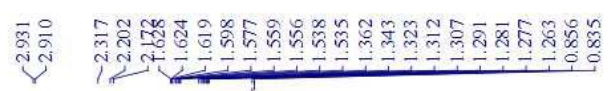
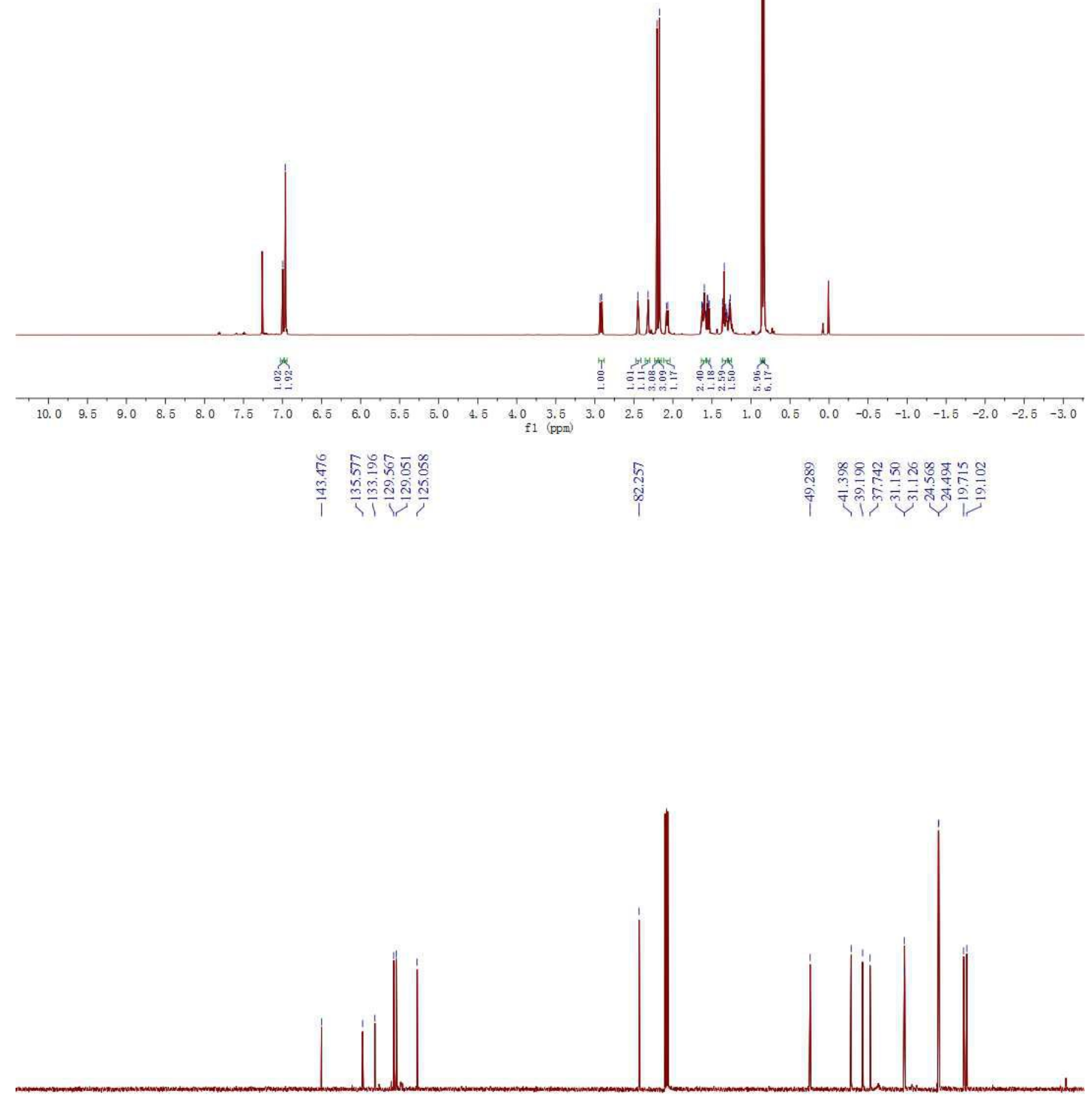

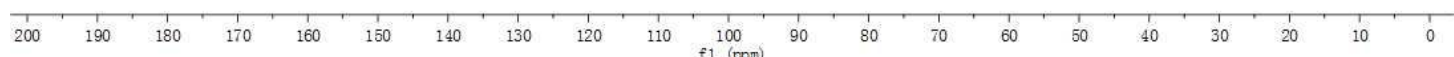




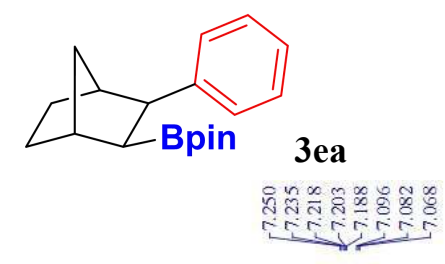

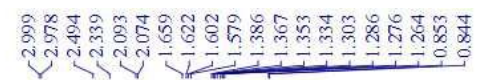
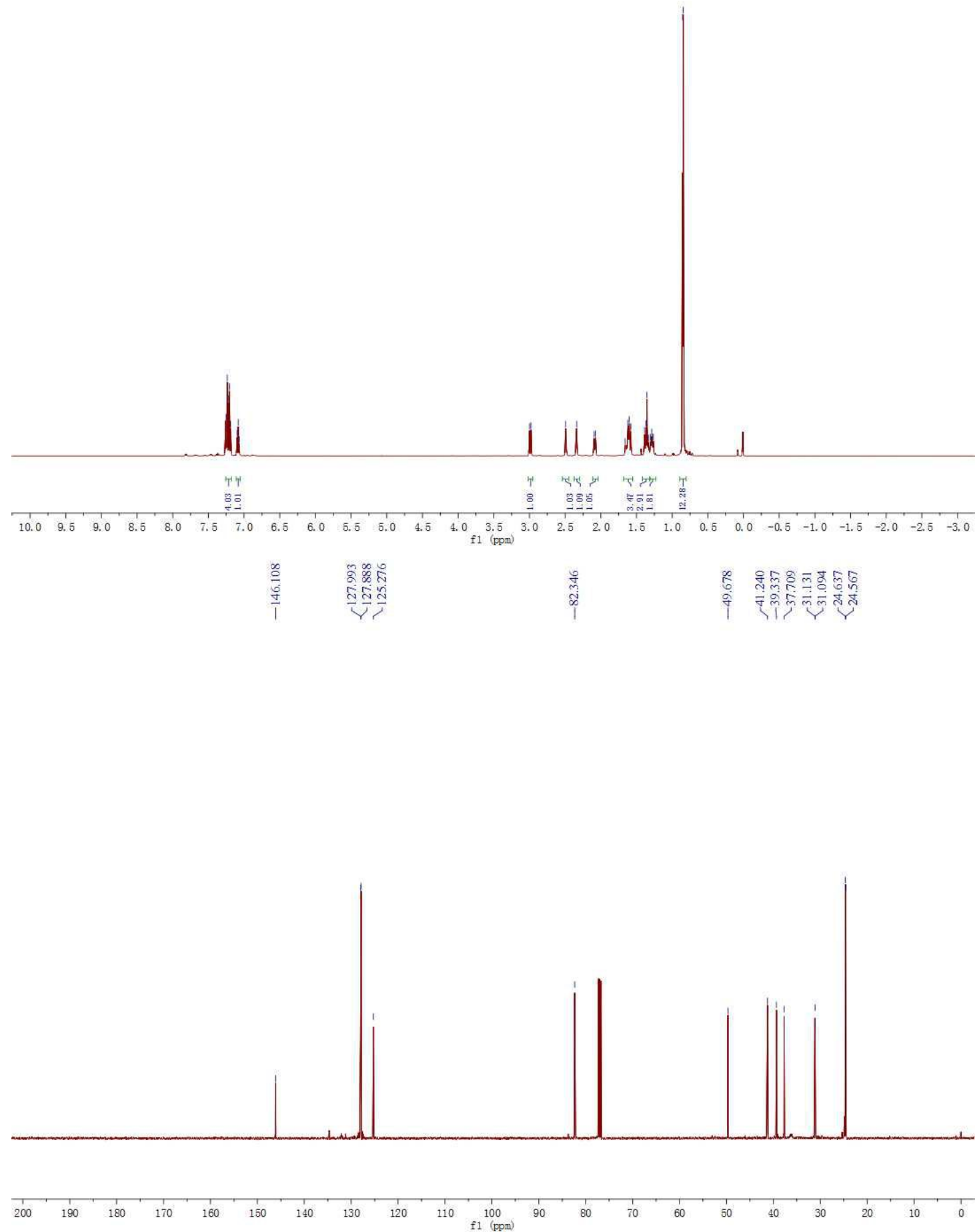


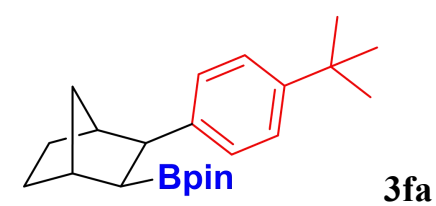

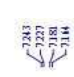

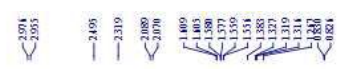
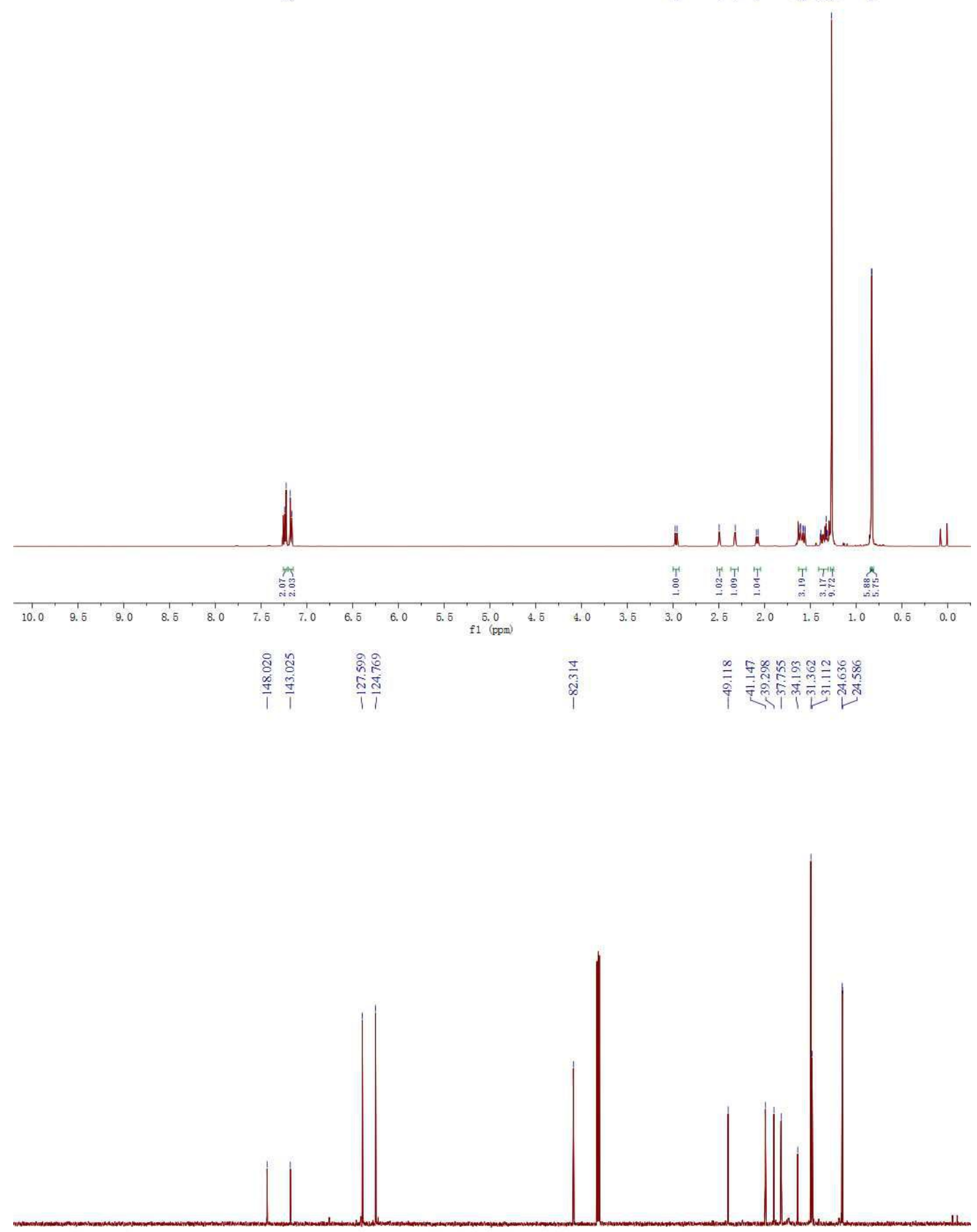

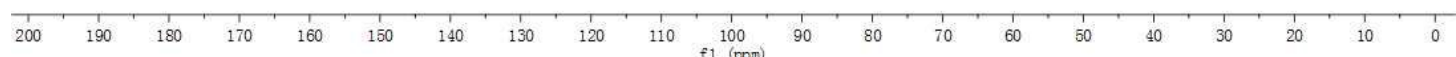



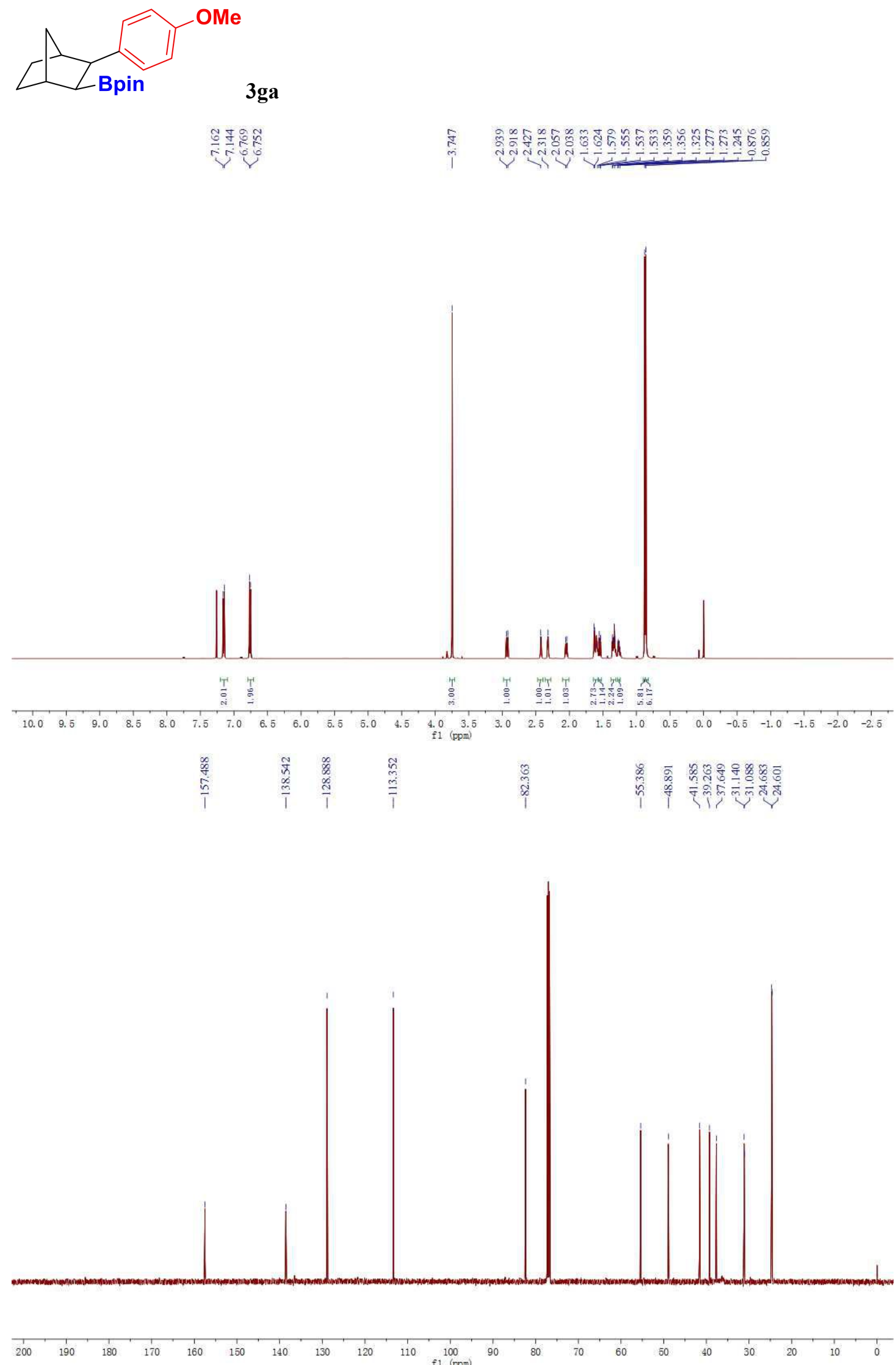
3ha

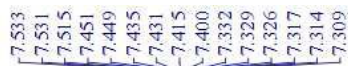

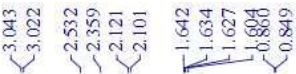

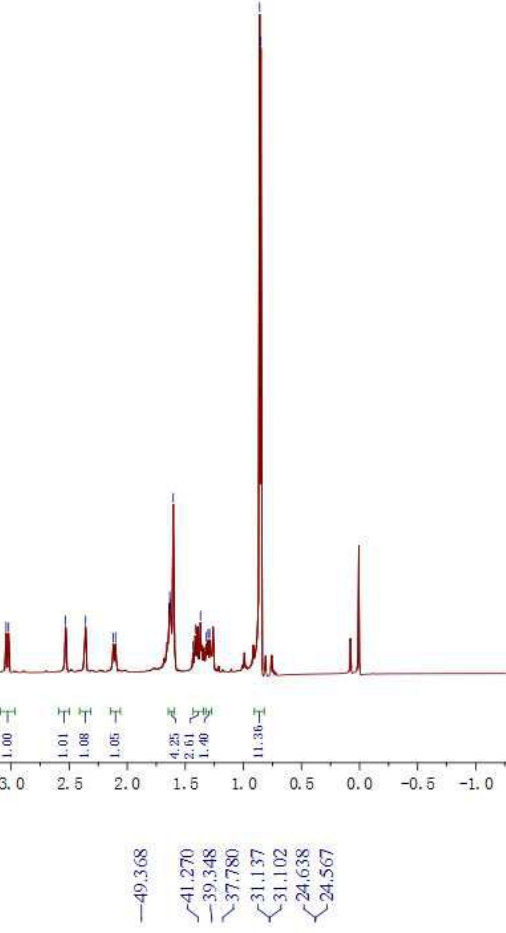

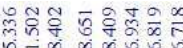

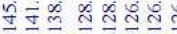

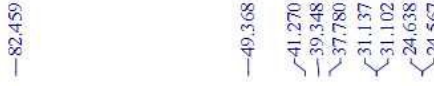
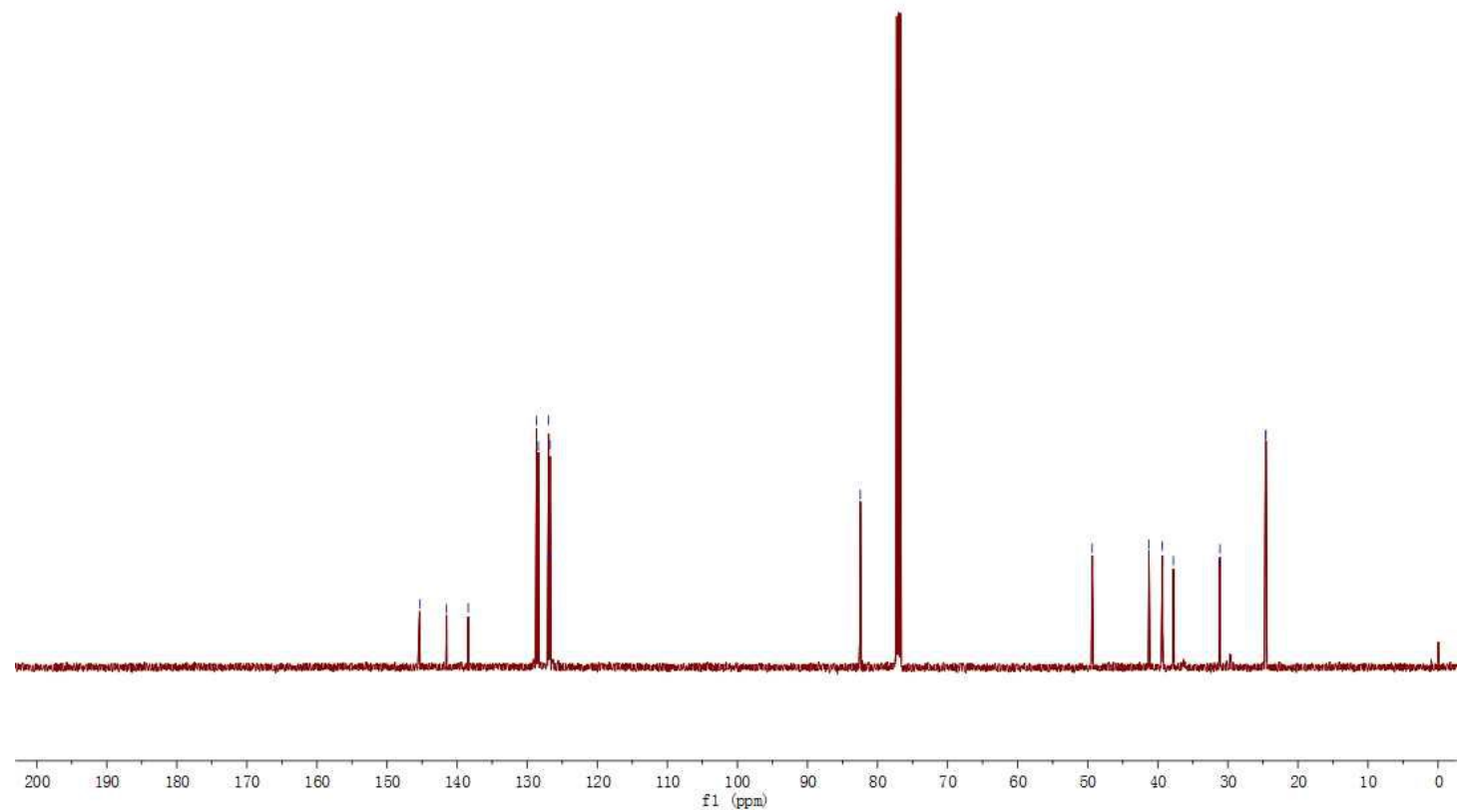


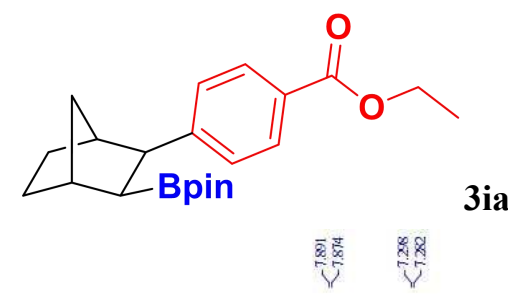

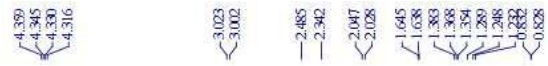
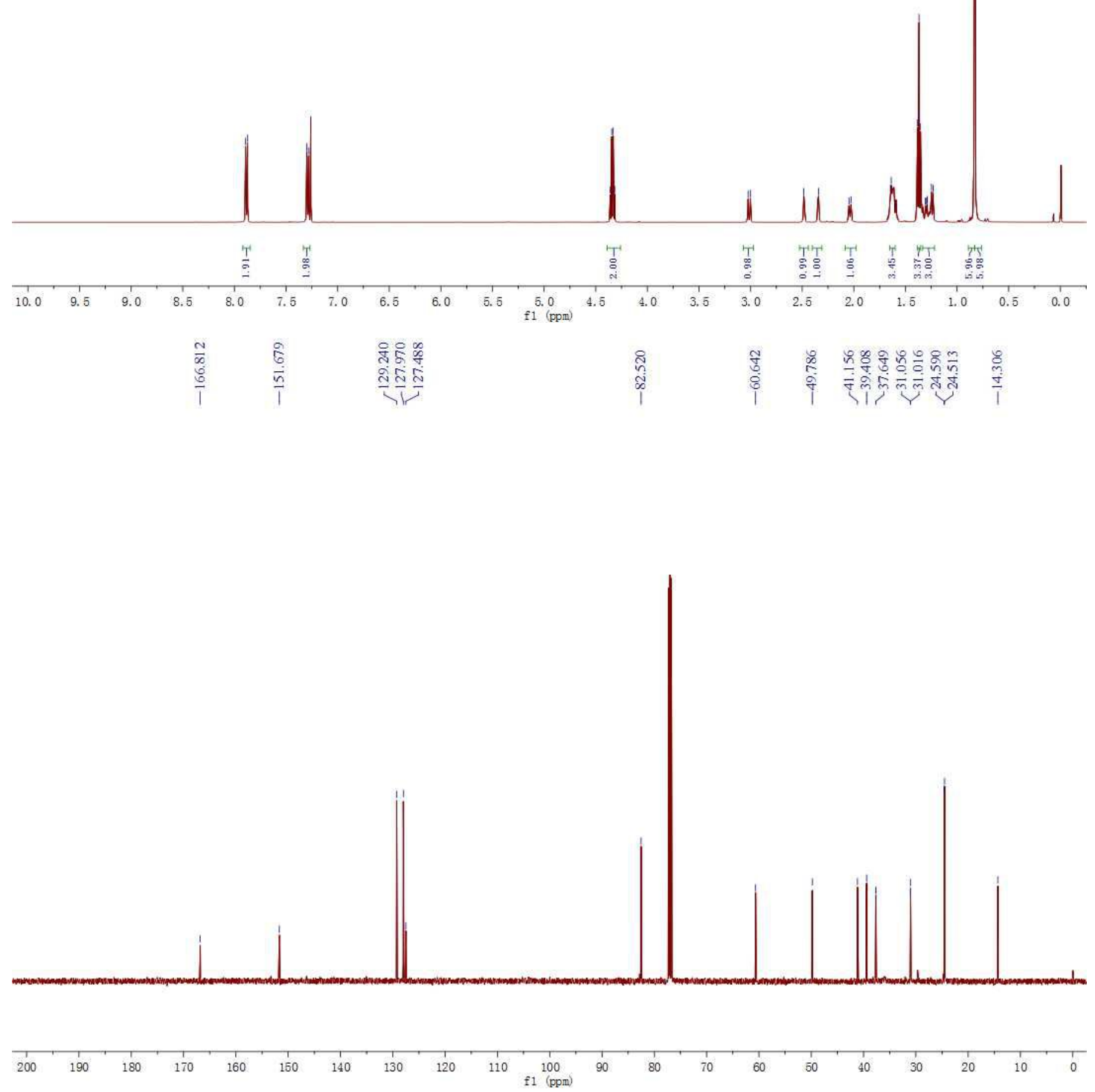


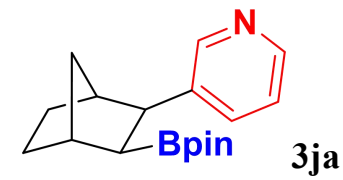

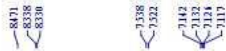

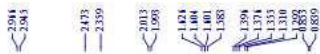
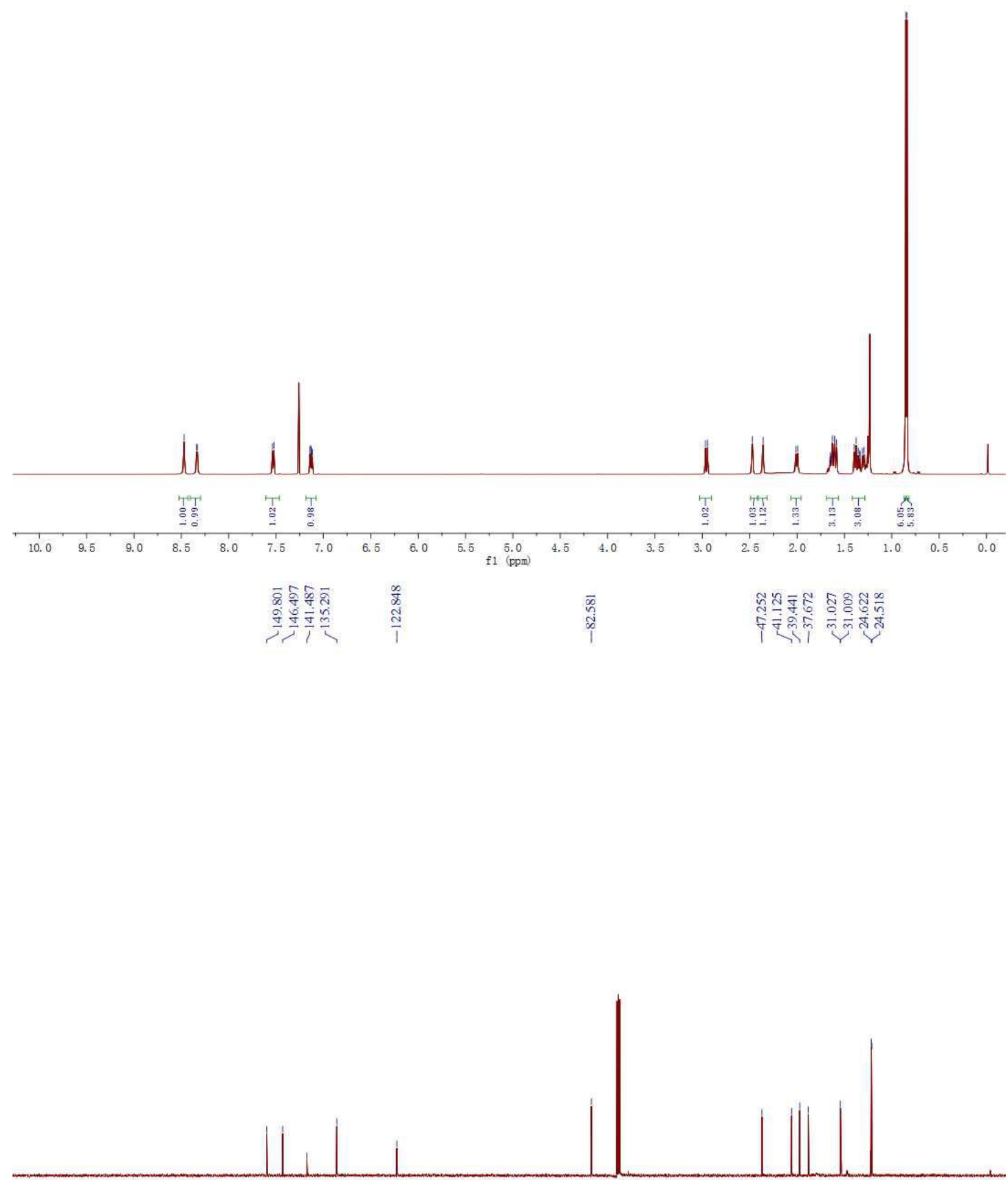

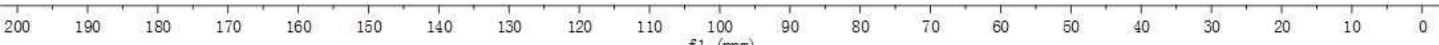




\section{$\mathrm{A}_{\text {Bpin }}^{\mathrm{N}}$}

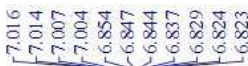

产
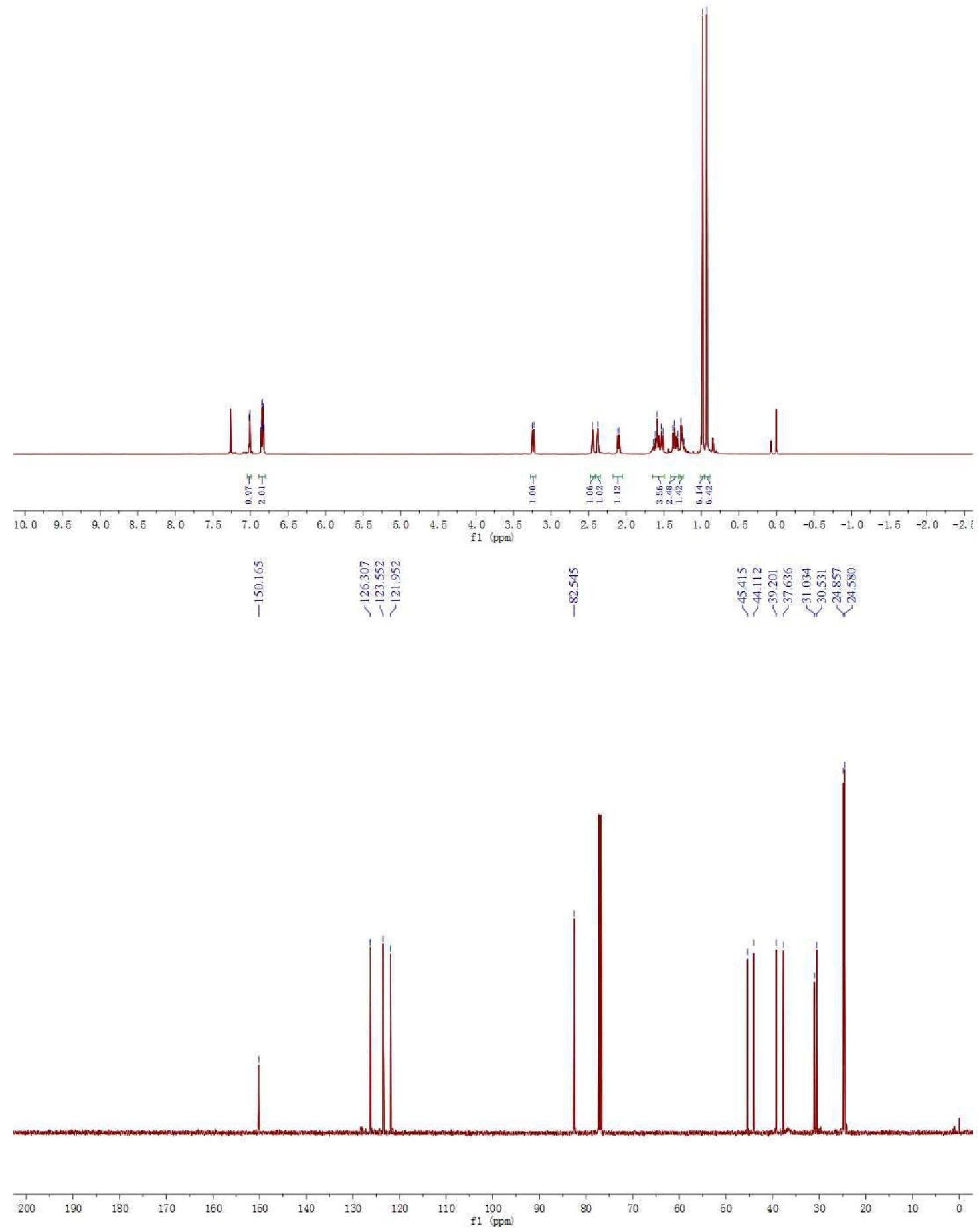
Labin

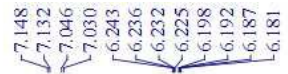
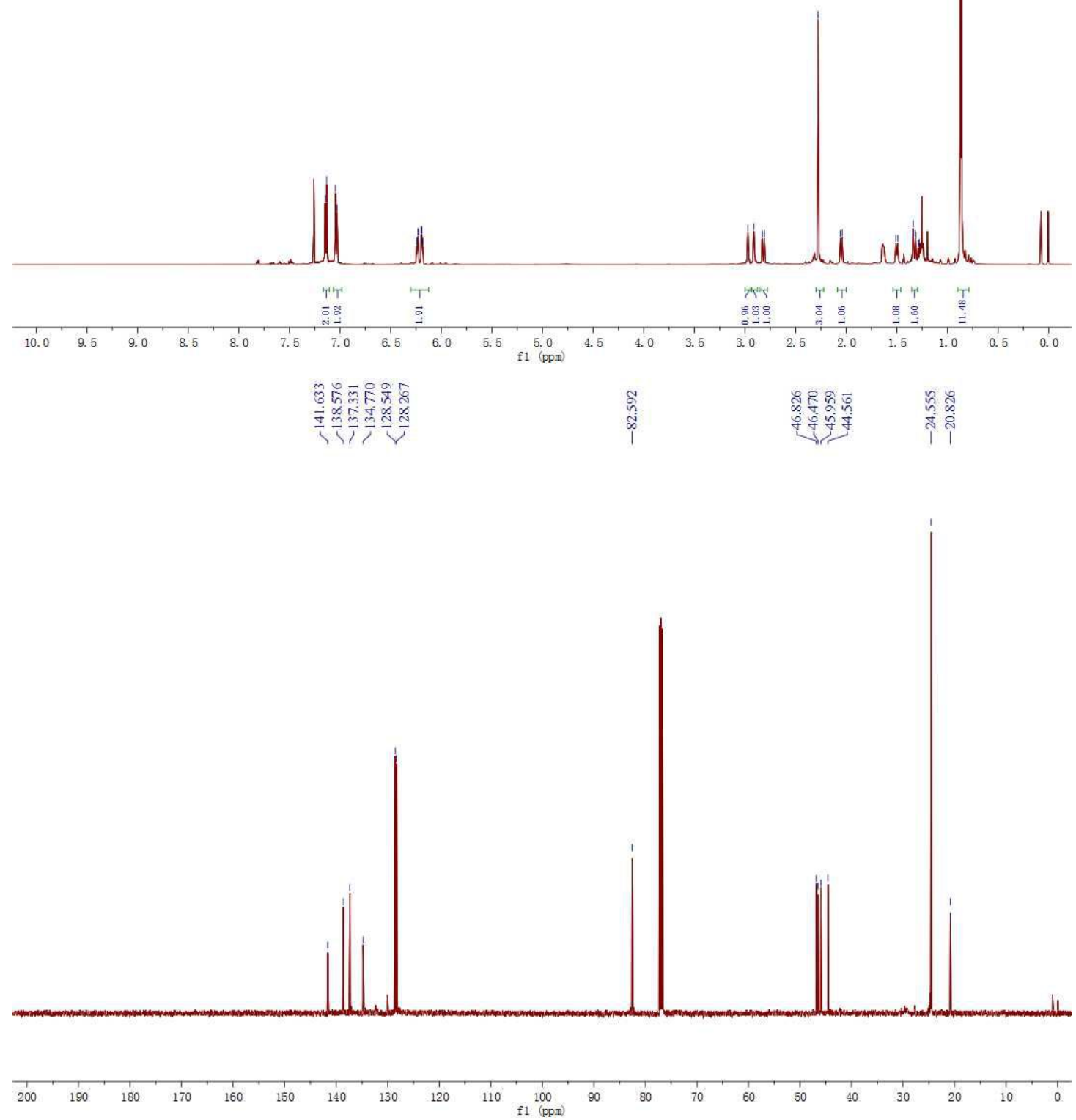


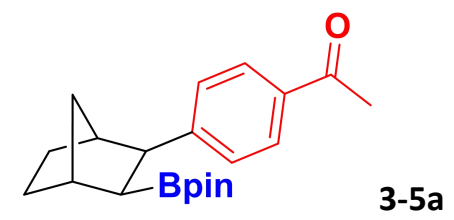

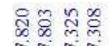

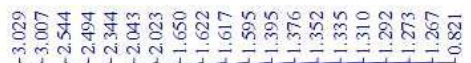
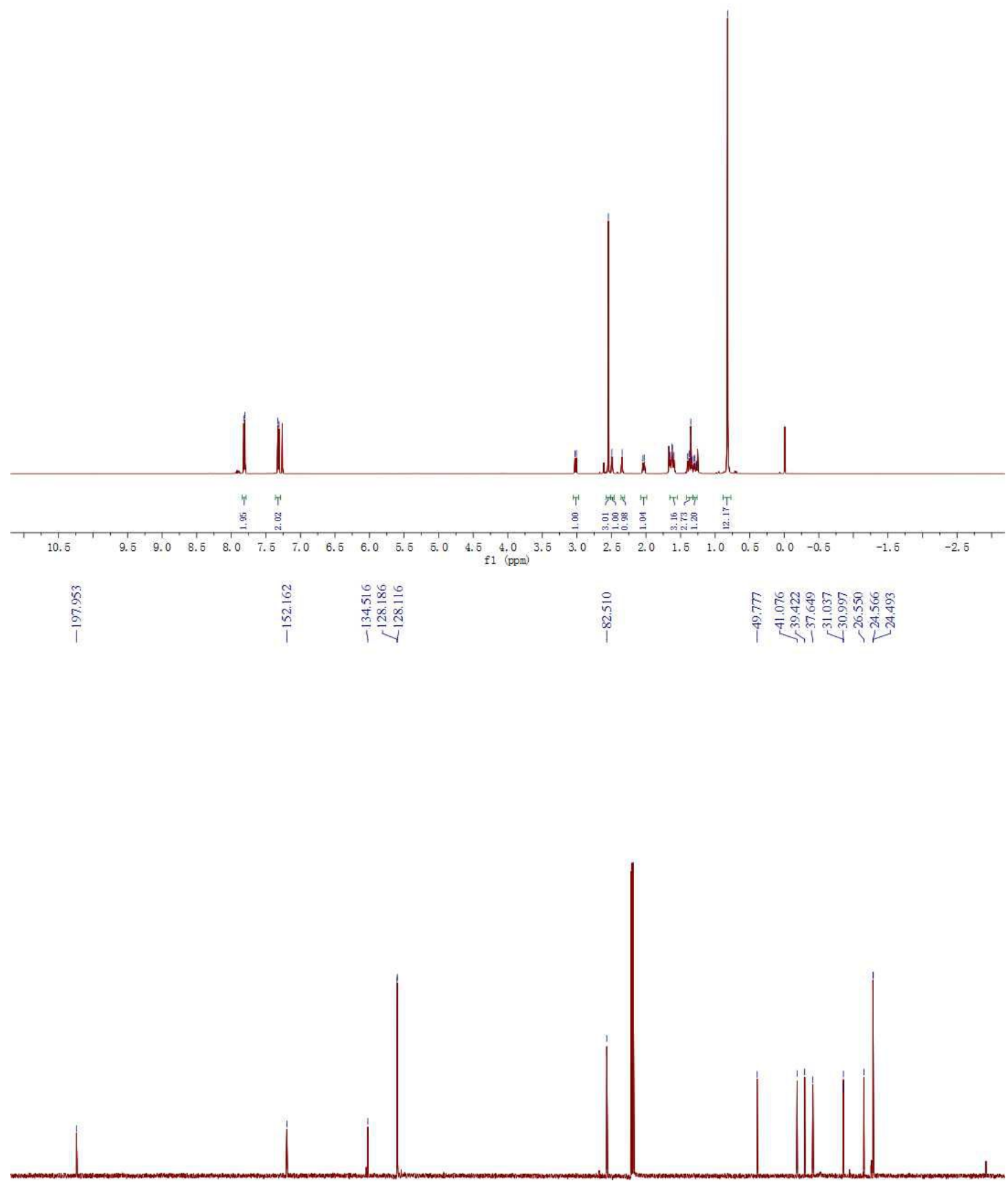

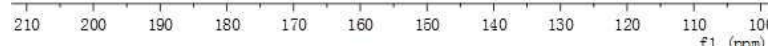




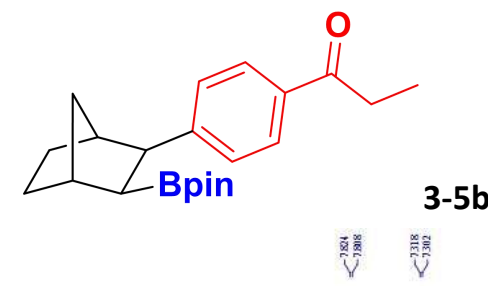

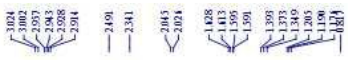
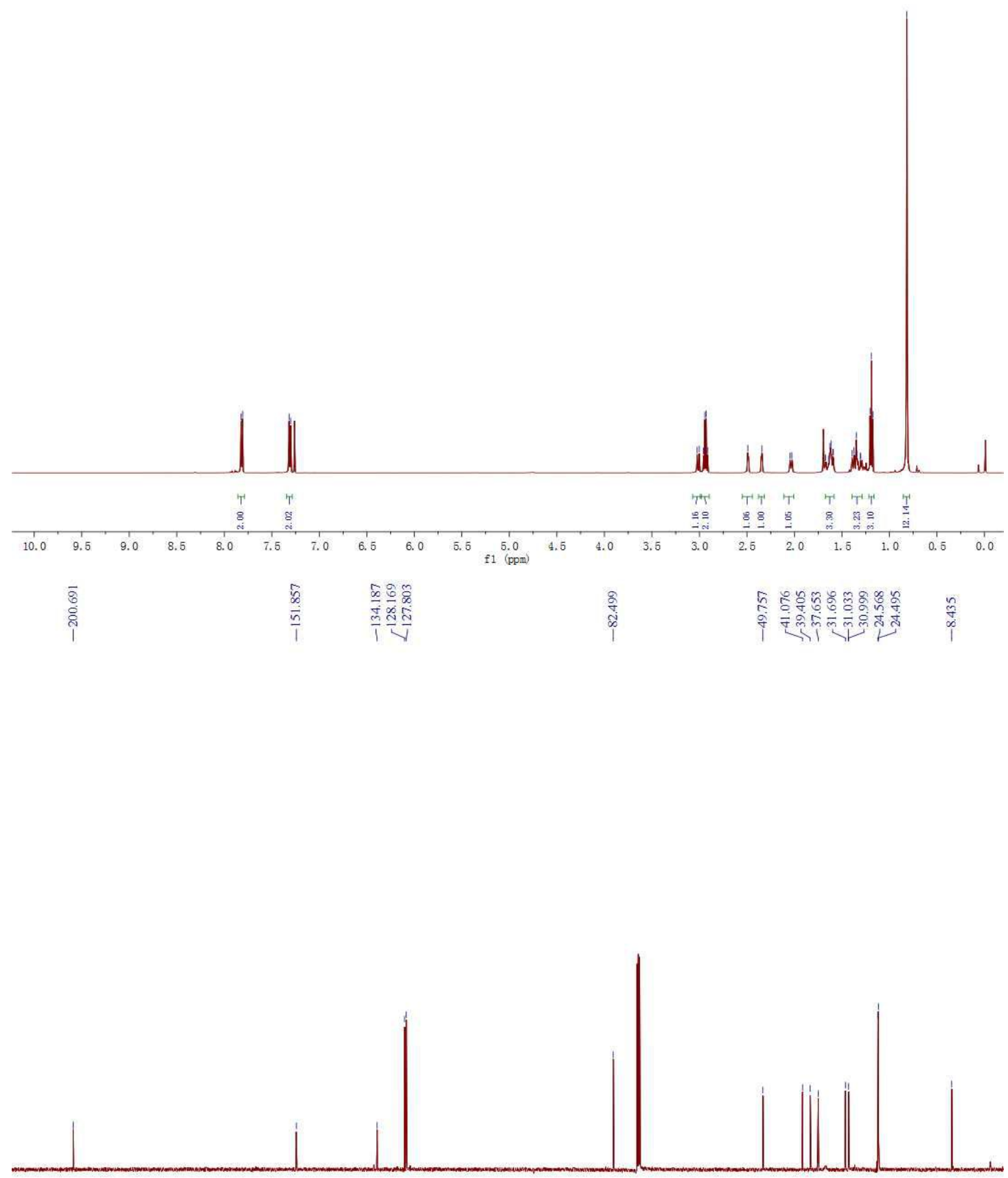

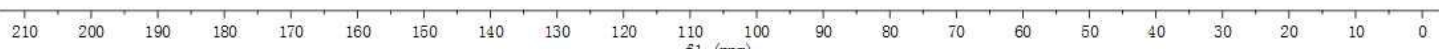


$C_{\text {Bpin }}$

空

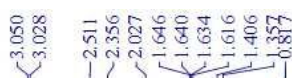
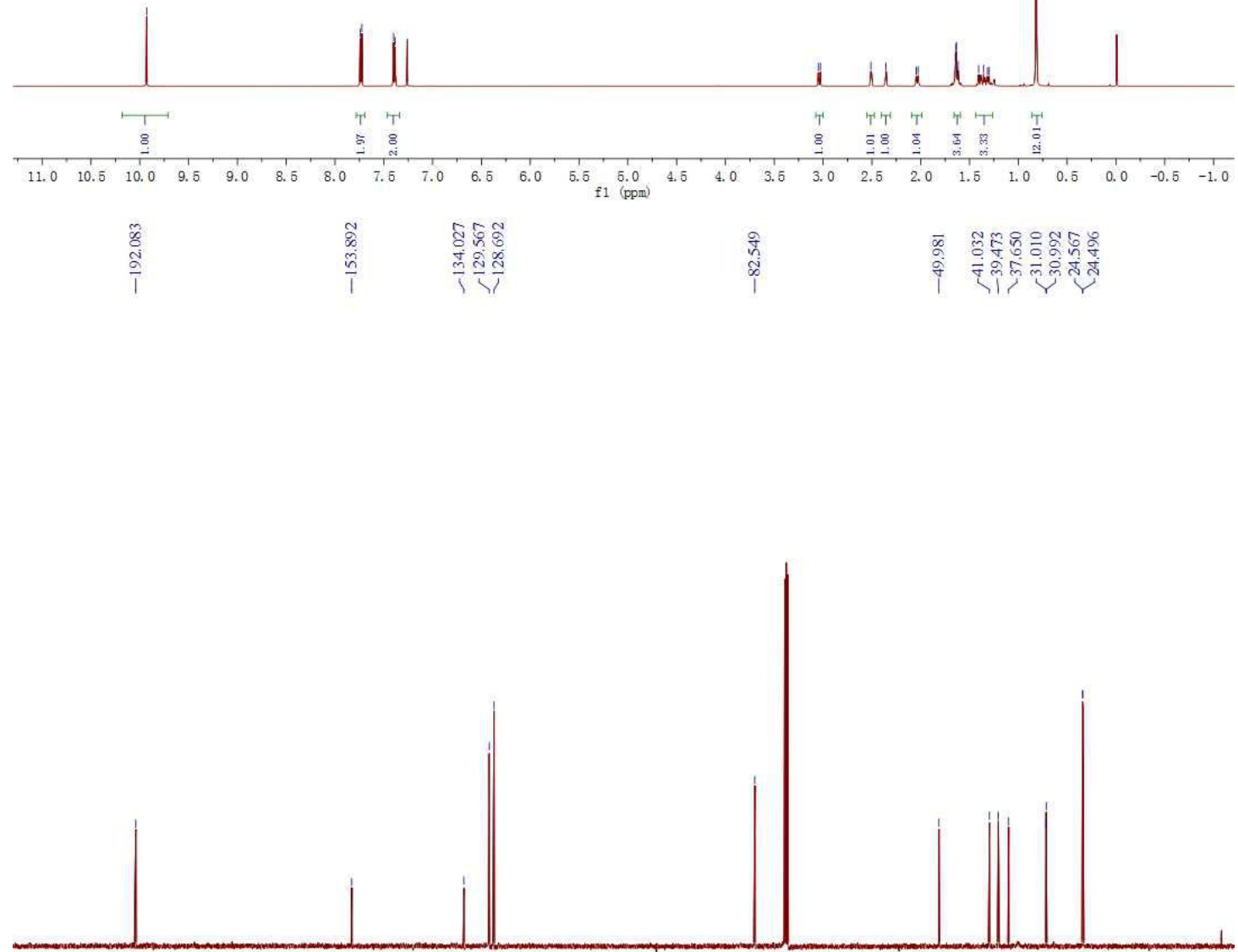

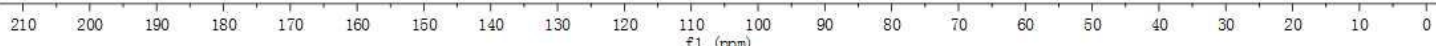



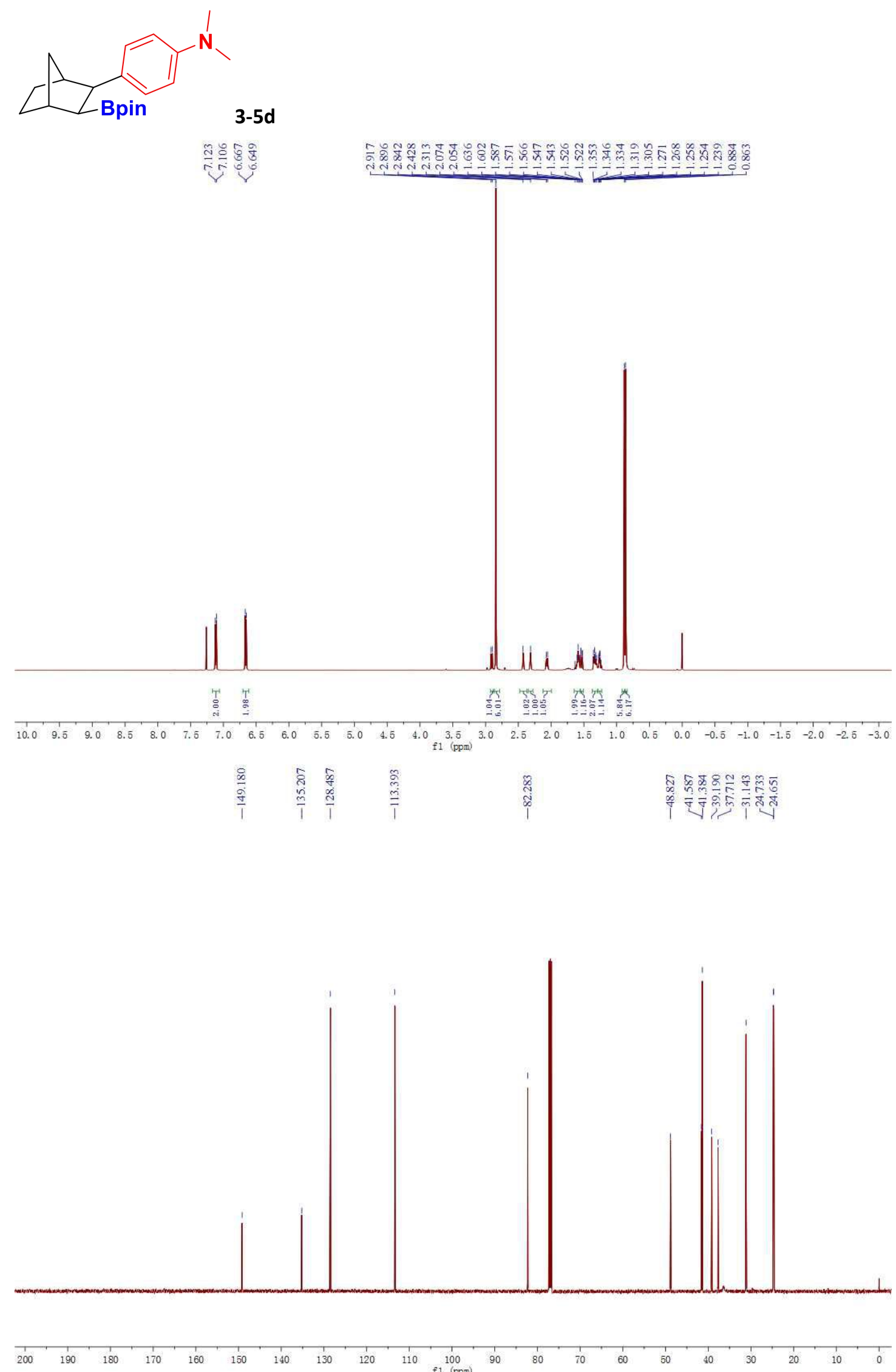
$\mathrm{C}_{3-5 \mathrm{e}}$

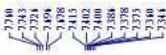

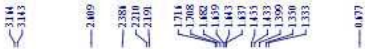

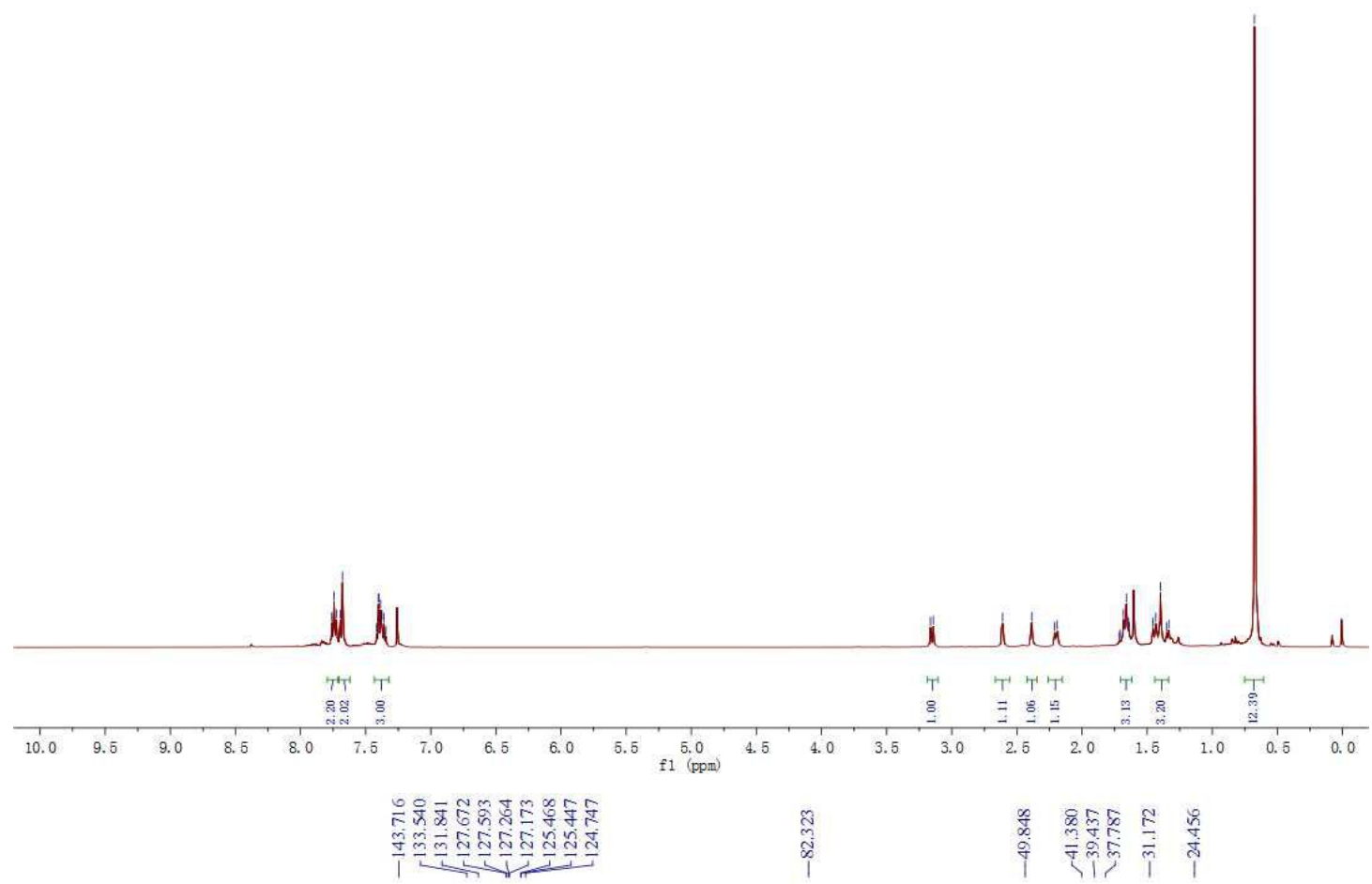

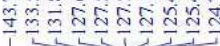

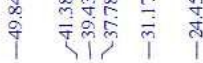

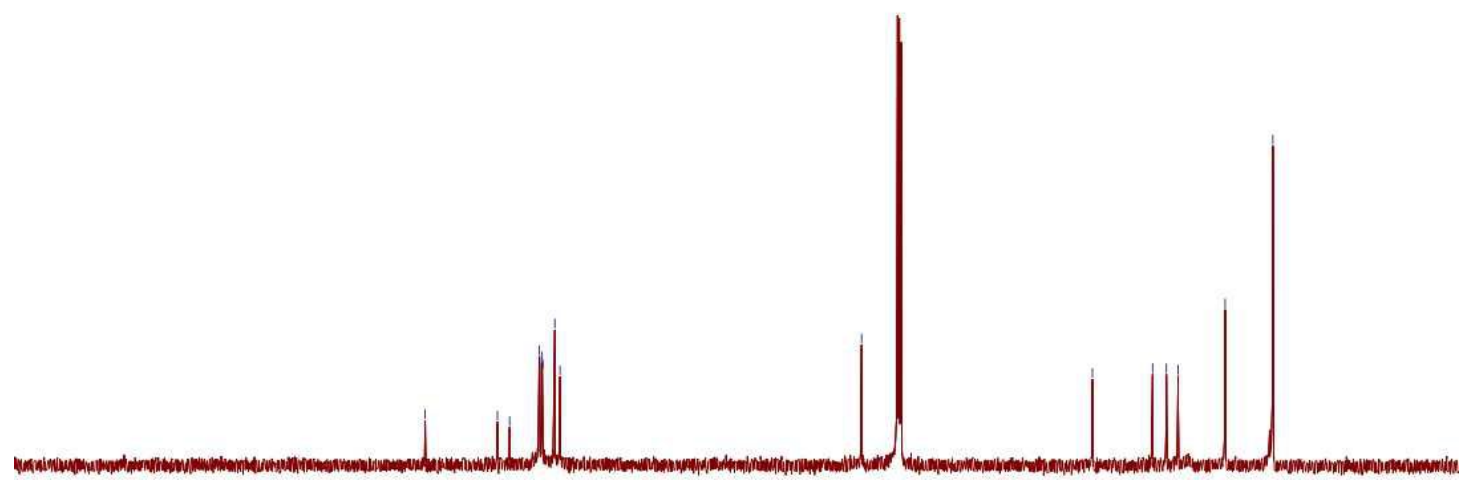

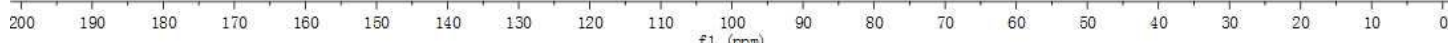




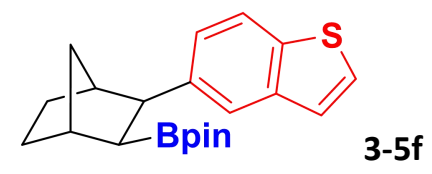

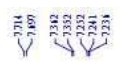

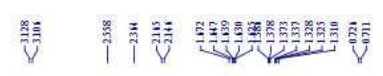
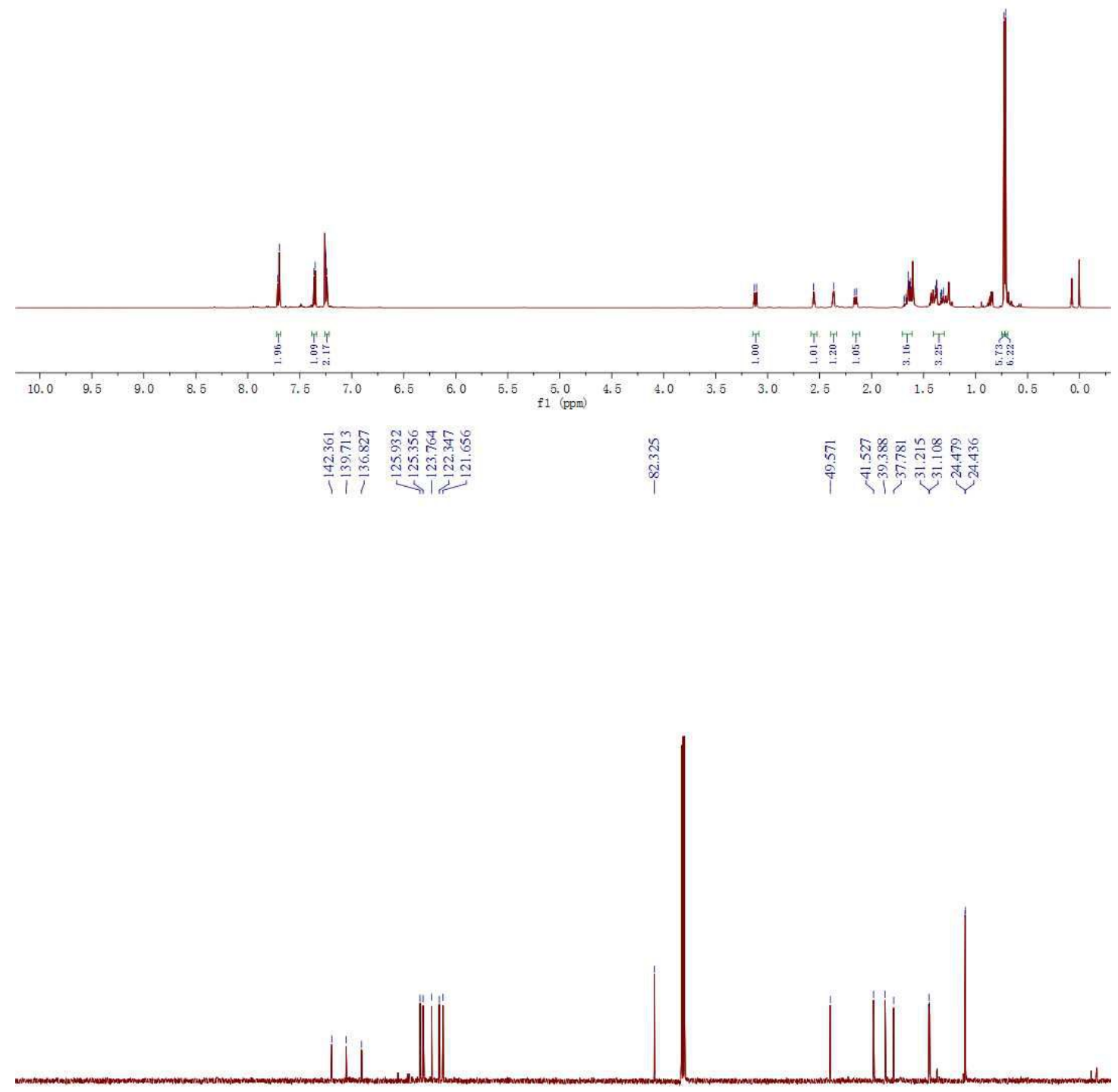

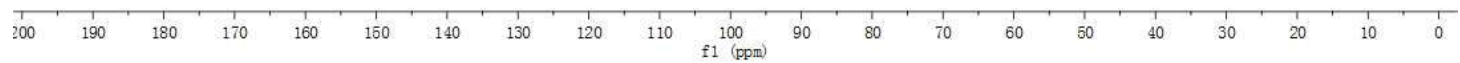




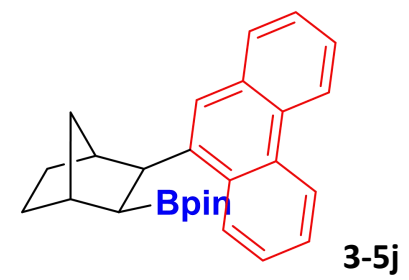

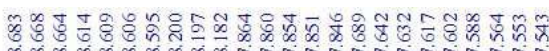

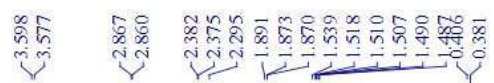

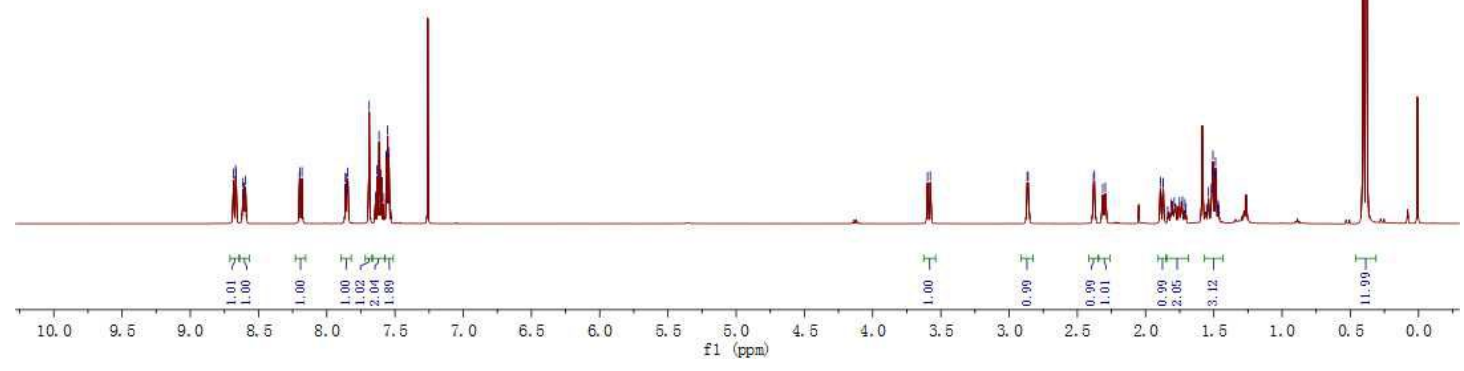

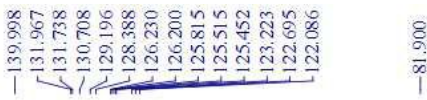

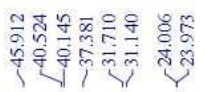

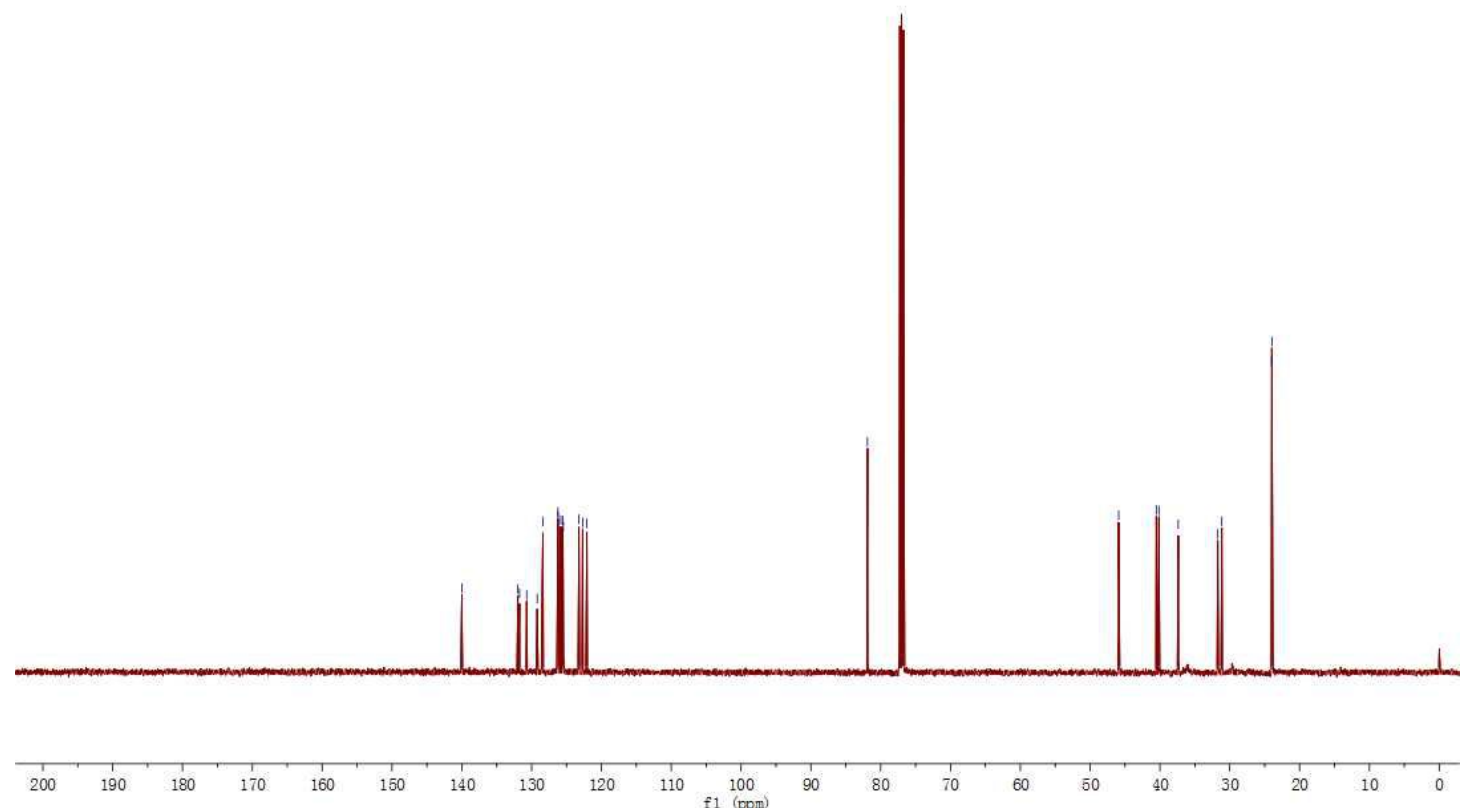


$\mathrm{COH}^{2}$

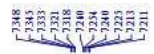

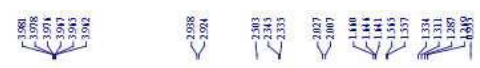
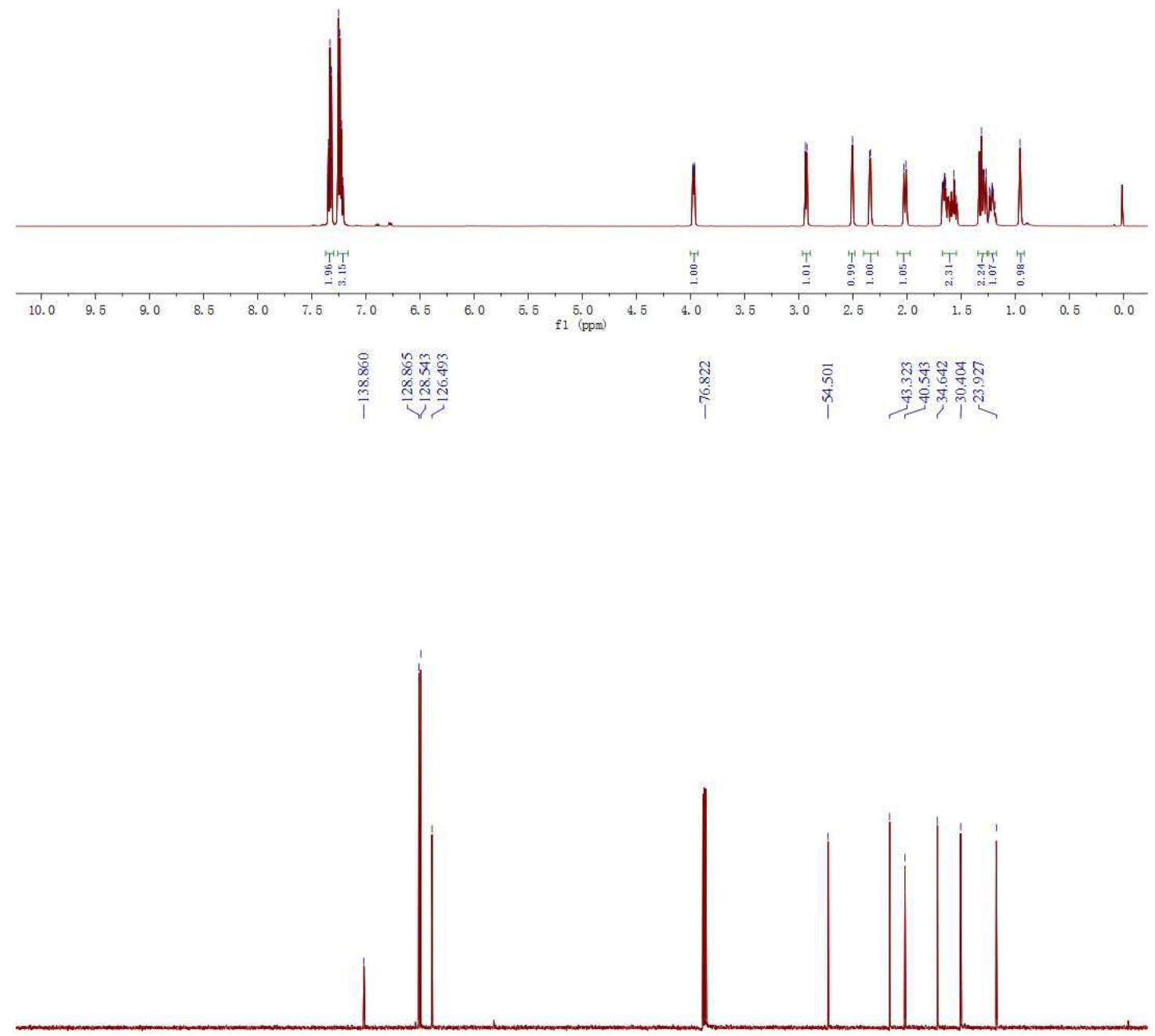

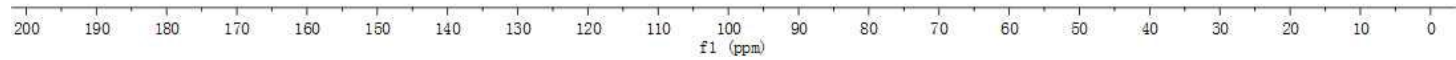



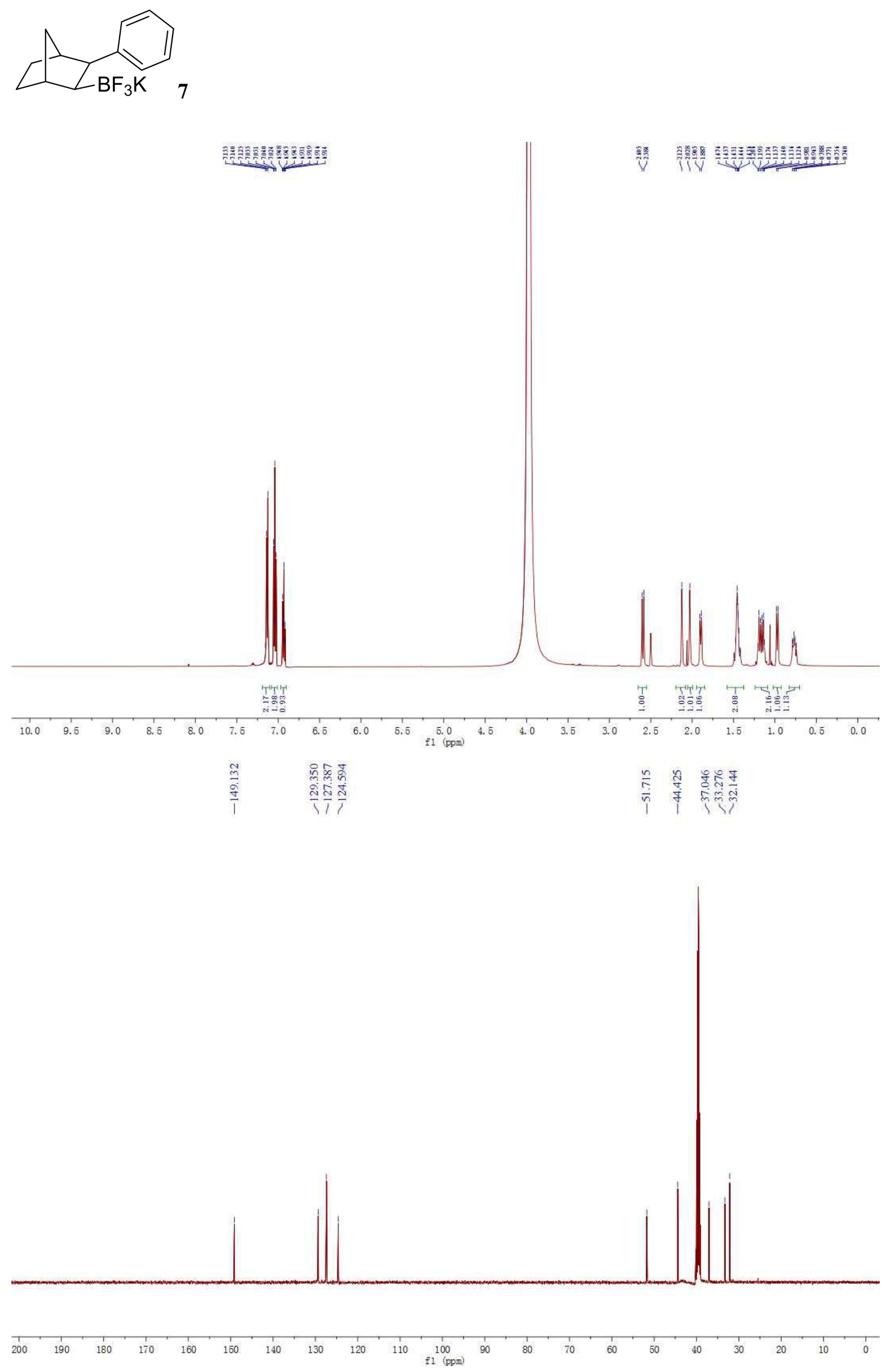
8

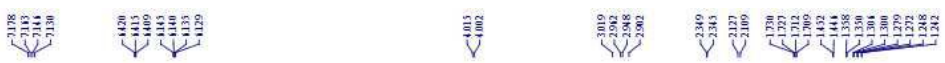
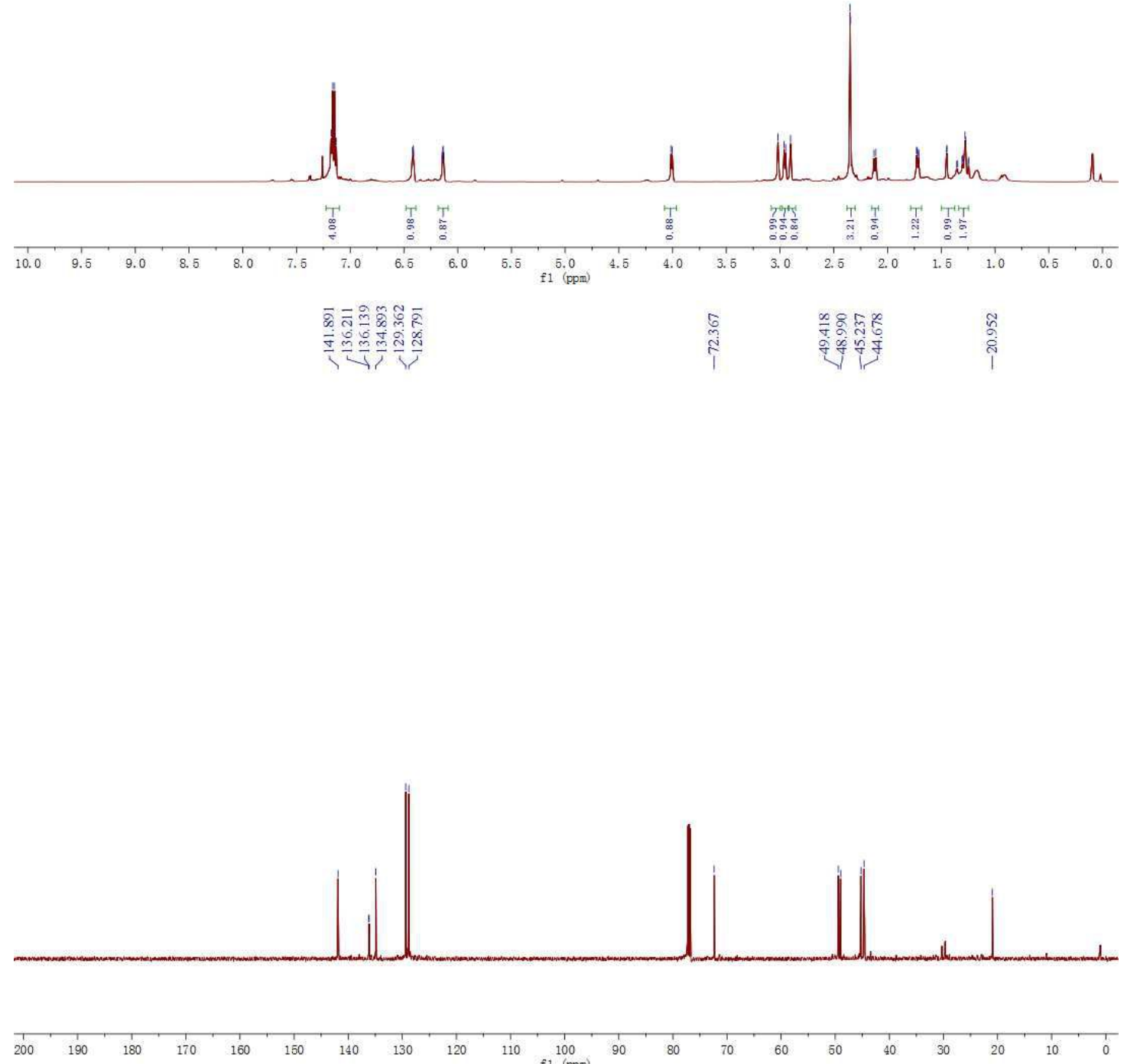
<smiles>C=CC1CC(C=C)C(c2ccc(C)cc2)C1O</smiles>

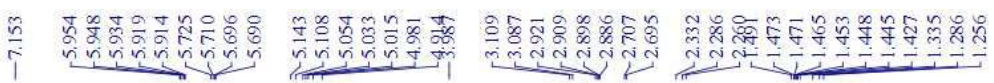
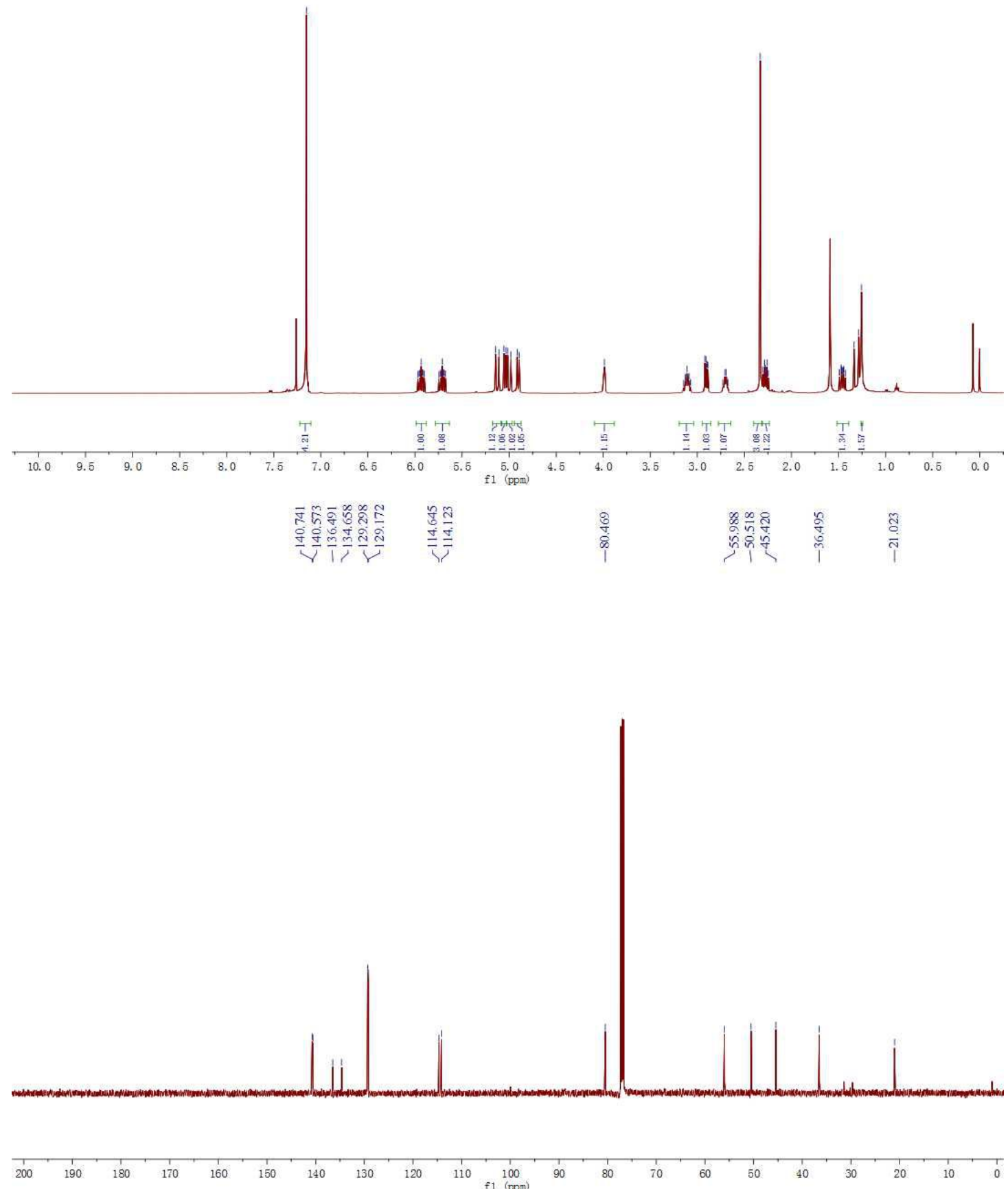